\title{
Assessment of tension wood detection based on shiny appearance for three poplar cultivars
}

\author{
Miguel Angel Badia, Frédéric Mothe, Thiéry Constant*, Gérard NePVeu \\ LERFOB UMR INRA-ENGREF No. 1092, Wood Quality Research Team, INRA Research Centre of Nancy, 54280 Champenoux, France
}

(Received 5 November 2003; accepted 31 August 2004)

\begin{abstract}
The shiny appearance of poplar tension wood was tested in order to detect and to quantify the amount of tension wood in nine crosscut discs. These carefully sawn discs came from different poplar clones: I214, Melone Carlo (I-MC) and Luisa Avanzo, exhibiting different patterns of tension wood distribution. The relevancy of the results was verified by means of 80 thin sections, $15 \mu \mathrm{m}$ thick and double stained with safranine and astra blue. Digital images of the discs and microscopic cuts were processed by image analysis to quantify the comparison. There was good agreement between both methods despite very different scales of observation. Eighty percent of the tension wood spots were detected by both methods and differences were mainly explained by human factors or inaccuracies in the macroscopic detection of small areas.
\end{abstract}

tension wood / poplar / macroscopic detection / microscopic measurement / image analysis / wood anatomy

Résumé - Évaluation de la détection du bois de tension basée sur son aspect nacré pour trois variétés de peuplier. L'apparence nacrée du bois de tension de peuplier est testée pour détecter et quantifier la quantité de bois de tension dans neuf rondelles. Ces rondelles sciées avec précaution proviennent de plusieurs clones de peuplier : 1214, Melone-Carlo (I-MC) et Luisa Avanzo, présentant des motifs différents de distribution du bois de tension. La pertinence du résultat est vérifiée, sur 80 coupes microscopiques, au moyen d'un double coloration safranine/ bleu astra. Des images numériques des rondelles et des coupes microscopiques ont été traitées par analyse d'image pour quantifier la comparaison. Il y a une bonne concordance entre les deux méthodes malgré des échelles d'observation très différentes. Quatre-vingts pour cent des zones de bois de tension ont été détectées par les deux méthodes, et les différences s'expliquent principalement par les imprécisions dues aux facteurs humains dans la détection macroscopique de petites zones.

bois de tension / peuplier / détection macroscopique / détection microscopique / analyse d'image / anatomie du bois

\section{INTRODUCTION}

Reaction wood is inherent to the formation of wood itself. For many years, researchers have agreed on the role of reaction wood coupled with growth stress, in the architectural development of the plant and the reorientation processes linked to gravitational or light solicitations. In the particular case of tension wood, which is the reaction wood produced by the majority of the dicotyledons, the definition of wood anatomists refers to the existence of a gelatinous layer (G layer), which replaces the secondary wall of the S3 layer and, sometimes, the S2 layer. This part of the secondary wall is mainly composed of cellulose (98\%), with microfibrils oriented parallel to the axis. According to several authors $[7,10,24]$, this flat orientation of microfibrils in the different layers explains why shrinkage is higher in tension wood, whereas the difference in chemical composition is the basis of the coloration test used to distinguish tension wood (TW) from normal wood (NW).
Most of the methods suitable for detecting TW take advantage of the difference in chemical composition or of cell wall organisation which is responsible for the different properties. Some of these methods are based of the narrow connection that exists between growth stress and reaction wood but cannot be considered as direct methods. Table I sums up different techniques found in scientific literature, indicating the basic principle of the method, its scale of detection, the extent to which the method is used, some of its limitations and advantages, and its applicability in the event of a large-scale sampling. Relevant references are included for the interested reader.

Within the framework of $\mathrm{Ph}$.D. research focusing on a better understanding of the existing relationship between tree shape and distribution of TW in poplar, we were looking for a quick identification of TW areas on a disk surface in order to be used on a large scale (302 disks) [1].

Colouring techniques seemed to be the best method for satisfying our objective. These tests can be carried out for different

* Corresponding author: constant@ nancy.inra.fr 
Table I. Different techniques used to detect tension wood. Methods are classified according to their level of detection, their advantages and disadvantages and, finally, their potential use on a large scale at this time (++: High, +: Medium, -: Low).

\begin{tabular}{|c|c|c|c|c|c|c|}
\hline & \multirow{2}{*}{$\begin{array}{l}\text { Level of } \\
\text { detection }\end{array}$} & \multicolumn{3}{|c|}{ Limitations } & \multirow{2}{*}{$\begin{array}{l}\text { Potential use on a } \\
\text { large scale nowadays }\end{array}$} & \multirow{2}{*}{ Literature } \\
\hline & & Time & Material & To know to make & & \\
\hline Microscopic sections & Microscopic & ++ & + & ++ & - & {$[4,5,30,33]$} \\
\hline Naked eye & Macroscopic & - & - & - & ++ & {$[8,19,25,29,31]$} \\
\hline Stains & Macroscopic & + & - & + & ++ & $\begin{array}{c}{[6,20,27], \text { Jensen cited }} \\
\text { by }[14,16,17]\end{array}$ \\
\hline Growth stress index & Macroscopic & + & + & ++ & ++ & {$[12,14,23,26,31,36]$} \\
\hline Longitudinal shrinkage & Micro/Macro & ++ & + & + & + & {$[7,14,18,32]$} \\
\hline Tangential shrinkage & Micro/Macro & ++ & + & ++ & - & {$[11,28,35]$} \\
\hline Density & Macroscopic & ++ & + & + & + & {$[2,18,21,27,31]$} \\
\hline Fibers length and yield & Microscopic & ++ & + & + & - & {$[2,6,8,15]$} \\
\hline Ultrasounds & Macroscopic & - & ++ & - & - & [15] \\
\hline X-Rays & Macroscopic & - & ++ & - & - & {$[22]$} \\
\hline Nuclear Magnetic Resonance & Macroscopic & - & ++ & - & - & {$[3]$} \\
\hline
\end{tabular}

scales: from microscopic sections (15-20 $\mu \mathrm{m}$ thick) to sawn disks. The most frequent colouring techniques for microscopic cuts make use of safranine to reveal the presence of lignin and of astra blue for crystalline cellulose [27, 33, 34].

The resulting colours are pink to red for cells containing lignin and blue for cellulose. For light-coloured woods like beech or poplar, another commonly used colouring technique, effective at a macroscopic level such as on a disk, uses zinc chloro-iodide, also known as Herzberg's reagent. Chlorine destroys hydrogen bonds between macro-polymers of cellulose and thus promotes the accumulation of iodine molecules in between. Jensen, 1962, quoted in [14], observed that "this product colours TW light purple to violet, and normal wood, yellow". But since iodine is degraded by light, the colour is transient and lasts for around $10 \mathrm{~min}[6,14,16]$.

In the transverse plane, several authors observed the shiny and silky appearance of tension wood in wood rings [8, 13, 16, $19,25,31]$, calling them "white rings". But, only Ritter et al. [29] used this criterion to detect tension wood and then to verify the presence of gelatinous fibres by using microscopy. This perception is intensified in the case of dried wood and an explanation advanced by Ritter was that the lower photosensitivity of lignin compared to that of cellulose was responsible.

After several attempts with Herzberg's solution, despite its frequent use in published results [6, 14, 16, 20, 27], we found that this method was not so efficient. The analysis of TW distribution in the disk was difficult to perform in some cases and the presence of colour did not significantly improve the perception of the distribution resulting from the glossy zones.

This paper deals with the visual detection of TW, based of its shiny aspect, observed on the surface of carefully sawn disks, and its comparison with results from well-identified microscopic cuts coloured by safranine and astra blue.

\section{MATERIALS AND METHODS}

Nine freshly sawn disks from eight poplar trees were selected in order to verify the quality of the macroscopic identification of TW by naked eye using coloured microscopic sections. These disks were a sub-set of a wider sampling (302 disks) selected in order to model the occurrence of tension wood in three poplar cultivars: I214, LuisaAvanzo and Melone-Carlo (I-MC). These trees were located in Spain, in Valle del Cinca (Aragon).

Three tree-shape indexes were defined on the basis of a tree shape inventory [9]: straight, leaned, and flexuous. One specimen per shape index was finally chosen to model tension wood. However, for this specific study (comparison of macroscopic and microscopic tension wood identification) 9 disks coming from 8 trees were selected. The straight I214 tree had not been sampled because of its low TW content. Nearly all disks where sampled at breast height (1 m 30) except one sampled at $11.5 \mathrm{~m}$ height. Table II shows the shape indexes of the trees sampled and the disks selected per tree.

\subsection{Macroscopic method}

Detection by the naked eye was performed by using the highest reflection of some areas, assumed to be composed of TW, under a lowangle natural light (Fig. 1). These areas were identified by means of a copying pencil (KOH-I-NOOR Hardmuth AG TM $1561 \mathrm{M}$ - Austria) directly on the disk surface, where the smallest areas measured $5 \mathrm{~mm}$ in the tangential direction and $1 \mathrm{~mm}$ in the radial one (i.e. thickness of the line). They were then transferred onto a transparent Mylar film containing additional information such as pith location and annual ring limits, using pens of different colours. The transparent Mylar films were scanned at 100dpi resolution corresponding to $245 \times 254 \mu \mathrm{m}$ square pixels. These images were cleaned using the Corel Photo paint software. Then, to quantify the areas of TW identified within each ring, Visilog 5.3 image analysis software was used. It was easy to separate them because of the different colours used to identify the features on the transparent sheet. Each pixel was identified according to its position, its type of wood: NW or TW, and the ring number. On the basis 


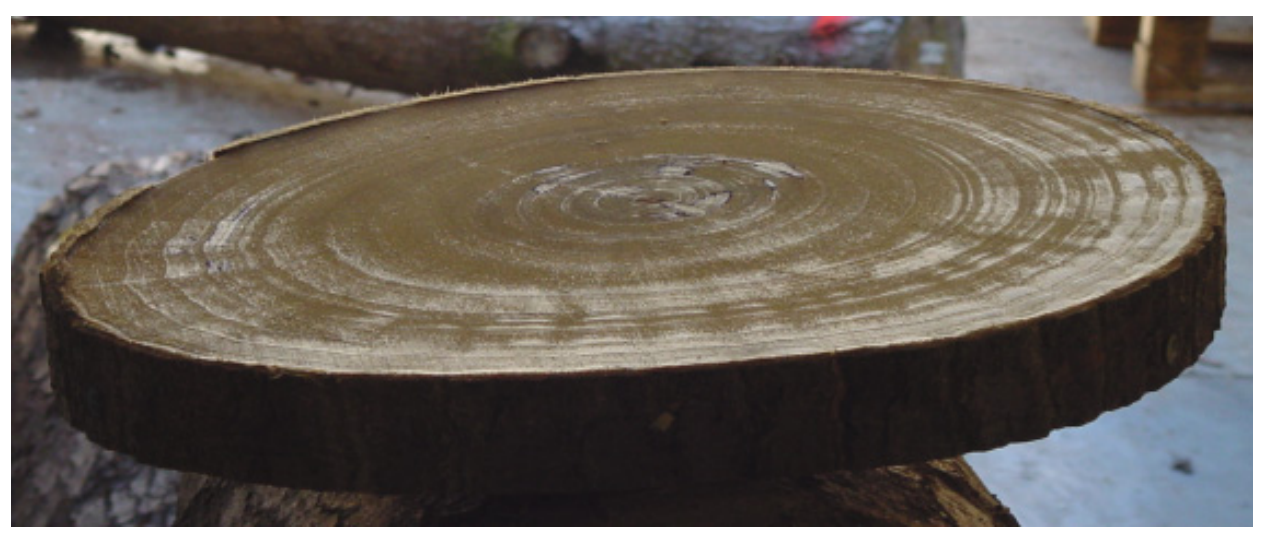

Figure 1. Tension wood areas from the Melone-Carlo cultivars viewed under a low-angle natural light.

Table II. Radii studied in order to compare the microscopic measurements of tension wood to the macroscopic measurements (naked eye): Type I: they showed a rather homogeneous area of supposed TW; Type II: radius which did not show any shiny zone except in well identified growth rings; Type III: they presented a special pattern of TW distribution.

\begin{tabular}{|c|c|c|c|c|c|}
\hline \multirow{2}{*}{ Cultivars } & \multirow{2}{*}{ Shape-index } & \multirow{2}{*}{ Disk height } & \multicolumn{3}{|c|}{ Radii } \\
\hline & & & Type I & Type II & Type III \\
\hline \multirow{2}{*}{$\mathrm{I}-214$} & Leaned & $1 \mathrm{~m} 30$ & 1 & 1 & 1 \\
\hline & Flexuous & $1 \mathrm{~m} 30$ & 1 & 1 & 0 \\
\hline \multirow{4}{*}{ Luisa Avanzo } & Straight & $1 \mathrm{~m} 30$ & 1 & 1 & 0 \\
\hline & Leaned* & $1 \mathrm{~m} 30$ & 1 & 1 & 1 \\
\hline & Leaned* & $11 \mathrm{~m} 50$ & 1 & 1 & 1 \\
\hline & Flexuous & $1 \mathrm{~m} 30$ & 1 & 1 & 0 \\
\hline \multirow{3}{*}{ I-MC } & Straight & $1 \mathrm{~m} 30$ & 1 & 1 & 0 \\
\hline & Leaned & $1 \mathrm{~m} 30$ & 1 & 1 & 1 \\
\hline & Flexuous & $1 \mathrm{~m} 30$ & 1 & 0 & 0 \\
\hline
\end{tabular}

\footnotetext{
* From the same tree.
}

of this information, TW ratios could be easily computed, regardless of the area of the whole disc or the annual ring.

\subsection{Microscopic method}

The purpose of the comparison with coloured microscopic sections was three-fold. Firstly, when TW is visually detected within a ring, can its presence be confirmed by microscopic analysis? Secondly, is there any TW zone overlooked by the visual assessment? Thirdly, can the size of an area be correctly assessed by the visual method, even for small areas? To answer these questions, three types of wood-strips or radii, ranging from 120 to $210 \mathrm{~mm}$, were cut in radial direction from the disks. Type I radii were selected because they showed a rather homogeneous area of supposed TW. Type II did not show large shiny zone in the radius except in well identified growth rings. Type III radii were not systematically sampled but when they were, they presented a special pattern of TW distribution (tangential discontinuity, for instance). From the 21 radii studied from the nine disks, 9 were type I, 8 type II and 4 type III (see Tab. II).

The 21 radii obtained were divided in 80 microscopic sections, 4 to $5 \mathrm{~mm}$ width in tangential direction and 4 to $5 \mathrm{~cm}$ in radial direction in order to produce thin sections by means of a microtome. These thin sections, between 15-20 $\mu \mathrm{m}$, were then coloured with astra blue and safranine and impregnated with Canada balsam. After being mounted on slides, they were scanned in RGB images at 2000 dpi, which corresponds to a square pixel of $12.7 \times 12.7 \mu \mathrm{m}$. After scanning, the 80 microscopic sections were carefully identified and superimposed on the disk, as shown on Figures 2 to 5, in order to obtain the 21 initial radii. The annual ring limits were drawn on the digital images by using the graphic editor, Corel Photo-Paint. Visilog 5.3 image analysis software was then used to quantify the area occupied by TW in each ring. The algorithm was based on the subtraction of the red component of the image from the blue one. This operation enhances the distinction between TW and NW. A common threshold was then used to separate them. This value was deduced without ambiguity from histograms where pixels were identified as belonging to NW or TW. Nevertheless, in order to obtain area values comparable to those detected by the naked eye (where areas of TW detected correspond to gelatinous fibres and surrounding vessels), vessels adjacent to gelatinous fibres were aggregated with them by a closing procedure during the image analysis. This procedure dilates gelatinous fibre zones $0.2 \mathrm{~mm}$ away, then it merges the vessels situated in this border to the gelatinous fibres. 


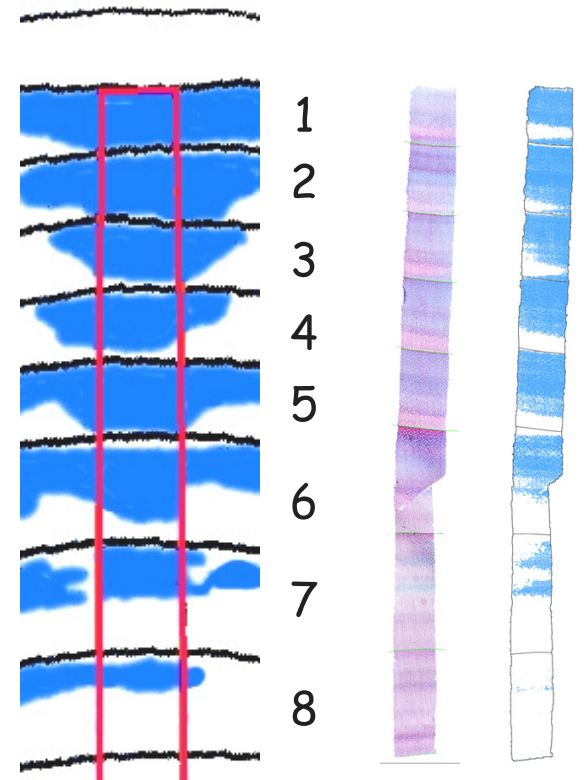

Figure 2. I_2R04_1

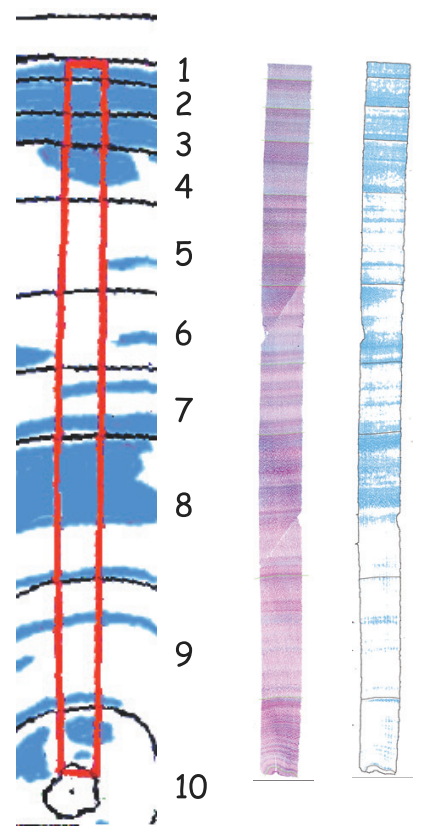

Figure 3. LA2R28_1

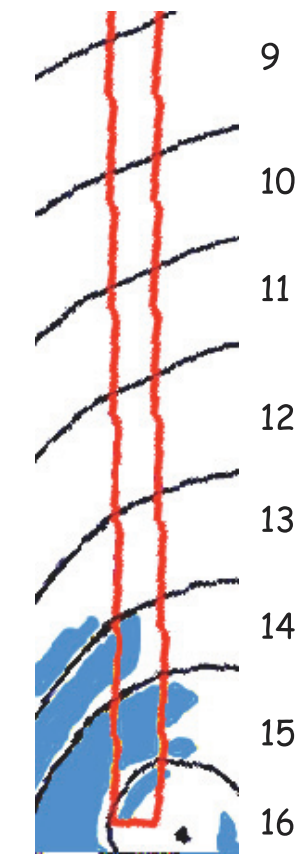

Figure 4. MCIR04_2

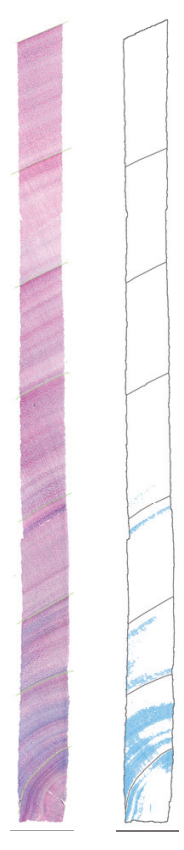

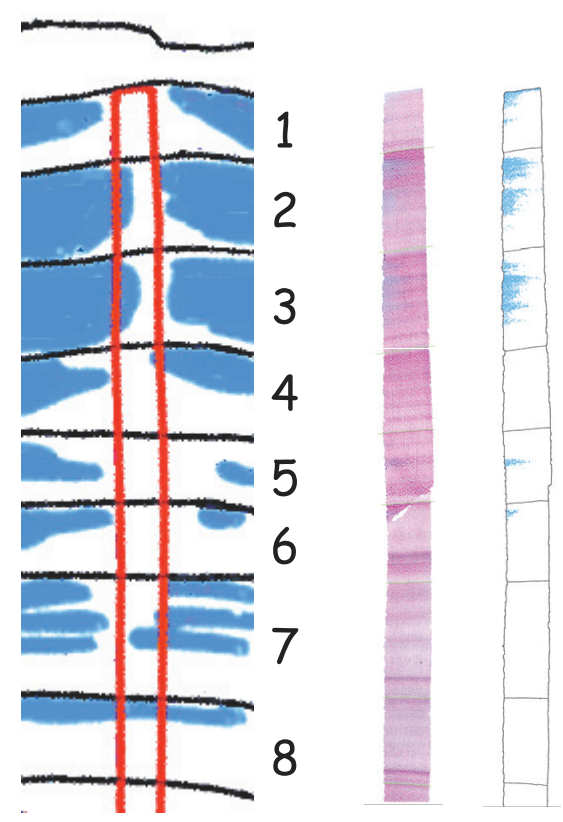

Figure 5. MC2R04_3

Figures 2-5. Four examples of visual comparisons between macroscopic detection, microscopic slices and image analyse identification of tension wood. Figures 2 and 3 illustrate two Type I radii; Figure 4 illustrates a Type II radius and Figure 5, a Type III radius. 
Table III. Means of macroscopic and microscopic percentage of tension wood and $p$-values from Student's $t$ test.

\begin{tabular}{lcccc}
\hline & $N$ & Mean $\mathrm{TW}_{\text {mac }}(\%)$ & Mean $\mathrm{TW}_{\text {mic }}(\%)$ & $p$-value \\
\hline 3 radius types & 315 & 8.43 & 6.6 & 0.111 \\
Type 1 & 137 & 16.1 & 3.5 & 0.051 \\
Type 2 & 122 & 2.3 & 4.3 & 0.579 \\
Type 3 & 56 & 3.9 & 4.8 & 0.678 \\
\hline
\end{tabular}

\subsection{Comparison of the macroscopic and microscopic methods}

In order to compare both methods on the same basis, by superimposition of the ring limits, thin sections were precisely identified on the transparent sheet. TW was detected by both methods for each area defined by two ring limits in the radial direction and by the limits of the thin sections in the tangential direction, and two ratios were finally obtained as follows:

$$
\begin{gathered}
\% T W_{\text {macro }}=\left(\frac{A_{\text {TW }}^{\text {Macro }}}{A_{\text {Ring }}^{\text {Macro }}}\right) \times 100 \\
\% T W_{\text {micro }}=\left(\frac{A\left(\begin{array}{c}
\text { Micro } \\
F G+\text { Adjacent Vessels }
\end{array}\right)}{A_{\text {Ring }}^{\text {Micro }}}\right) \times 100
\end{gathered}
$$

where $\mathrm{A}$ is an area, the exponent corresponds to the method and the suffix to the nature of the anatomical feature.

\section{RESULTS}

The visual comparison of the macroscopic and microscopic measurements of tension wood generally shows good agreement between both methods: as expected, the microscopic cross-sections issued from samples assumed to contain a lot of tension wood were strongly coloured in blue, indicating a high content of G-fibres; the samples where no tension wood was detected macroscopically resulted in red-coloured sections.

There was a strong correlation $\left(R^{2}=0.81\right)$ between tension wood ratios measured with both methods on the 21 samples (Fig. 6).

Moreover, as shown in Figures 2 to 5, macroscopic detection of tension wood seemed to be effective at the ring level: most of the large tension wood spots were correctly detected and Gfibres were almost always observed inside the manually drawn spots.

Upon closer observation, some discrepancies could be found in the case of small spots. In these cases, the size of the pen was close to the thickness of the tension wood band (e.g. Ring 8 in Fig. 2 where the line drawn is too thick, or Ring 9 in Fig. 3 where a thin band of tension wood was not considered by the operator).

The boundaries of the tension wood spots drawn by both methods do not match as can be seen on Figure 5. Observation of Rings 1, 5 and 6 shows that the line drawn around the spot does not correspond to the measurement frame where G-fibres were detected. On the other hand, in Ring 7, where no tension wood was microscopically observed, the line bordering the adjacent spot intersects with the measurement frame. In spite of those inaccuracies, the general feeling about Figure 5 is that

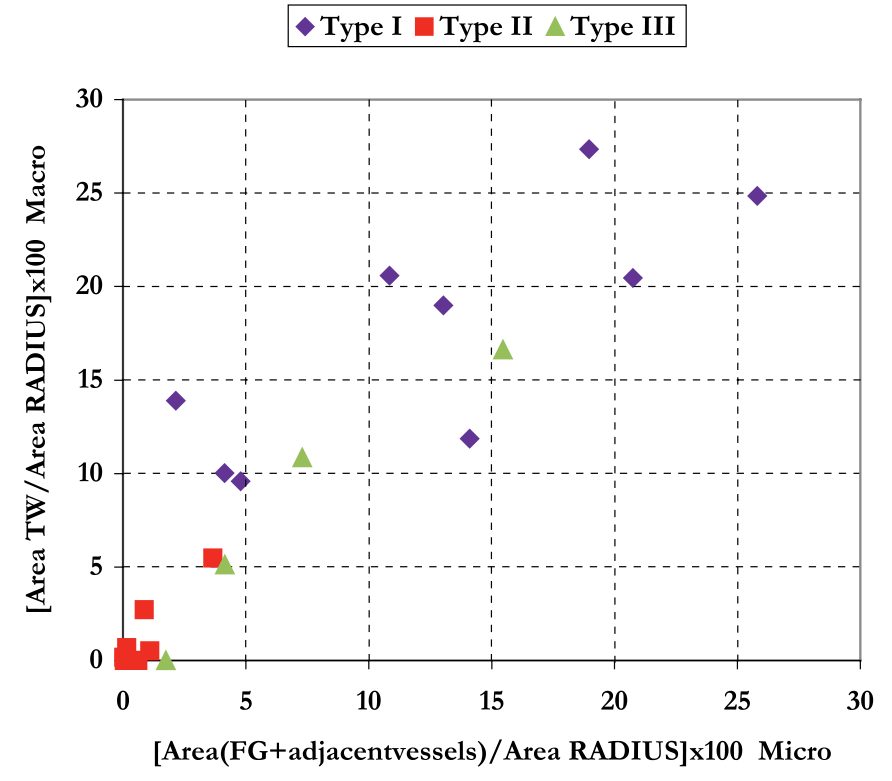

Figure 6. Macroscopic and microscopic tension wood percentage per radius for the 21 radii.

there is good agreement between both methods, particularly considering Rings 2 and 3.

The reliability of macroscopic detection for assessing tension wood content at the ring level is evaluated below by taking the microscopic tension wood area ratio (i.e. the area including G-fibres and adjacent vessels divided by the ring area) as a reference.

Considering the huge difference of scale between macroscopic and microscopic detection and the small size of the measured zone (ring width $\times 4$ to $5 \mathrm{~mm}$, i.e. 12 to $100 \mathrm{~mm}^{2}$ ), the direct comparison of the tension wood rates obtained with both methods (Fig. 7 and Tab. III) may be considered to be satisfactory the $R^{2}$ value is 0.57 and there are no significant difference between the methods according to the Student $t$-test. Regarding the different radii types, Type I, which corresponds to the radius were macroscopic detection showed a rather homogeneous area of TW, presents the more significant difference $(p$-value $=0.051)$ between macroscopic and microscopic identification of tension wood.

Meanwhile, it clearly appears on Figure 7 that the macroscopic method tends to overestimate the tension wood ratio, except for several points located near the horizontal axis.

The detailed observation of the concerned rings does not clearly explain the reason why macroscopic detection failed in 


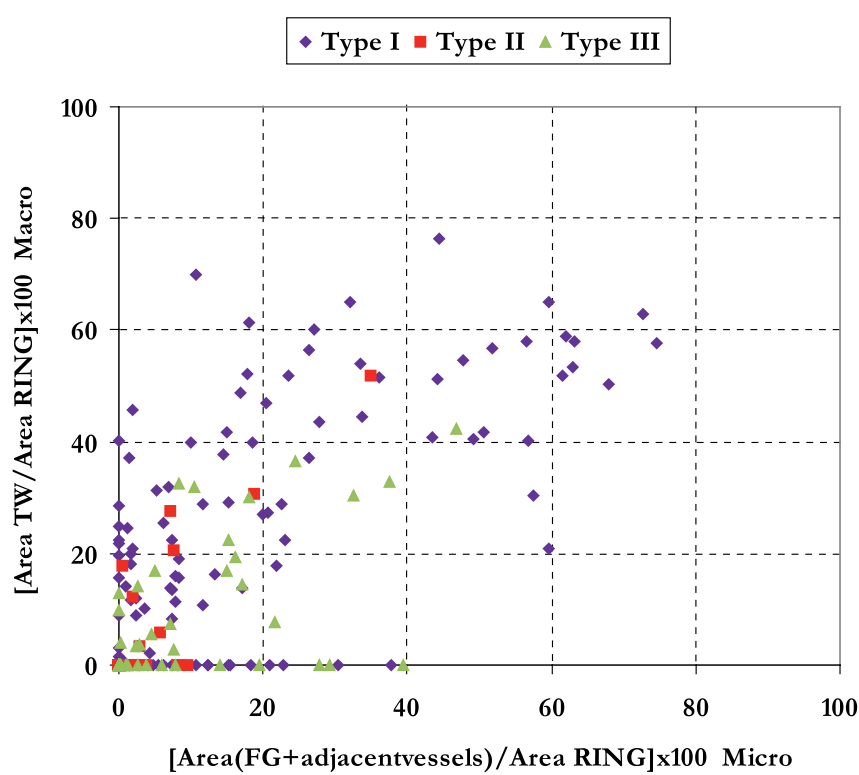

Figure 7. Relation between macroscopic and microscopic percentage of tension wood per ring.

these cases (see Ring 6 in Fig. 3, for example). It is suspected that this could be due to operator error, considering that most of the concerned rings belong to disk samples containing a large quantity of TW with a large number of distinct spots.

The overestimating trend observed for the remaining rings is typically a scale effect. Closer observation of the complex shape of tension wood zones on the right side and the rounded spots drawn on the left side in Figures 2 to 5 clearly reveals that the inevitable simplification of the shape by the operator always leads to an enlargement of the surface. Such an effect was partially - but not completely - compensated by the image analysis procedure used (by including the vessels in the G-fibre zones on the microscopic side and by using the middle of the drawn lines as boundaries on the macroscopic side).

No particular effect of sample Type I, II or III can be observed in Figure 7. As expected, most of the rings issued from Type II samples (i.e. assumed to be radii free of tension wood or in any case only present in a few growth rings) are nearly all superimposed onto the origin of the axes. Type III rings (i.e. framed by tension wood on both sides) do not clearly differ from Type I rings (i.e. special pattern of TW).

The cumulative histograms shown on Figure 8 help to explain the discrepancy between both measurements, particularly for low tension wood content samples: $65 \%$ of the rings were considered to be free of tension wood by the macroscopic method versus only $26 \%$ for the microscopic method. Within the range from $0 \%$ (excluded) to $6 \%$, where the curves intersect, the respective percentages are $37 \%$ (microscopic) and $3 \%$ (macroscopic).

These results lead us to consider the macroscopic data measured at the ring level as binary values: below a given threshold proportion, no tension wood is detected. A candidate for the threshold could be the value of $6 \%$ of tension wood, leading to the same amount of samples on each side for both methods.

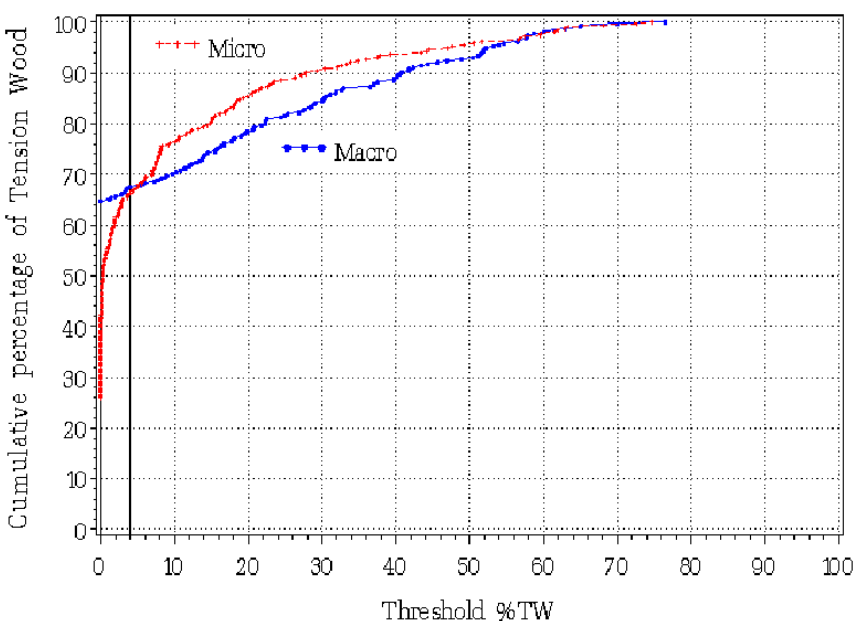

Figure 8. Cumulative distribution function of the tension wood percentage in both measurements: macroscopic and microscopic.

Table IV. Concordance and discordance identification between macroscopic and microscopic results.

\begin{tabular}{lccc}
\hline & \multicolumn{2}{c}{ Threshold_mic 4\% } \\
\cline { 3 - 4 } & & With & Without \\
\hline \multirow{2}{*}{ Threshold_mac 0\% } & With & 80 & 27 \\
& Without & 31 & 177 \\
\hline
\end{tabular}

Number of rings $=315 ;$ total error $(\%)=18.4$

Nevertheless, looking at the distributions curves (Fig. 7), it seems more natural to define a distinct threshold for each method: the only singular point for the macroscopic detection is at $0 \%$ content, and an inflexion point may be observed near $4 \%$ content for the microscopic method. Using this definition, the number of rings "with" and "without" tension wood remain consistent for both methods and the resulting agreement/disagreement table shows that macroscopic detection was successful in more than $80 \%$ of the cases (Tab. IV).

\section{CONCLUSIONS}

A fast macroscopic method for detecting tension wood on freshly sawn poplar disks was discussed. The method, based on the difference in shininess of tension wood and normal wood, was applied to nine poplar disks (I214, Luisa Avanzo and I-MC). The results obtained from 21 radial samples coming from these disks were compared to microscopic measurements of tension wood area ratio (including G-fibres and adjacent vessels) using the traditional "safranine - astra blue" coloration of cross sections.

A strong correlation between both measurements of the 21 samples was observed $\left(R^{2}=0.81\right)$. The comparison of the data gathered at the ring level (i.e. concerning 12 to $100 \mathrm{~mm}^{2}$, depending on ring width) does not show significant differences 
between both measurements. However, the analysis shows that the macroscopic method fails to detect tension wood in some rings and tends to overestimate the area of tension wood in general. Despite the very small tangential dimension of the measured surfaces (around $6 \mathrm{~mm}$ ), the method makes it possible to detect tension wood in $80 \%$ of the cases.

Considering these results, it is assumed that the proposed method may be applied for measuring tension wood distribution at the disk scale with good accuracy. However, as tension wood appears to be also very species dependent, the results of this work needs to find confirmation on other species.

A very similar method (using a simplified procedure for image analysis) was actually routinely applied to 302 disks of poplar within the framework of a study on the interrelations between tree shape and tension wood distribution [1].

Acknowledgements: We are most grateful to B. Jourez (DGRNE Gembloux-Belgium) for his useful comments about this work and to S. Garros (Lerfob INRA-ENGREF) for her assistance in laboratory work.

\section{REFERENCES}

[1] Badia M., Modélisation de la distribution du bois de tension dans une grume de Peuplier à partir de l'empilement tridimensionnel des cernes. Cas des cultivars I214, Luisa Avanzo et I-MC, Thèse de doctorat en Sciences du Bois, ENGREF, 2003, 215 p.

[2] Boury S., Estimation quantitative de la répartition du bois de tension chez le peuplier (Populus $\times$ euramericana $\mathrm{cv}$. I214) à partir de l'hétérogénéité circonférencielle de la densité du bois, Équipe Qualité des Bois-INRA, Nancy, 1993, 34 p.

[3] Bucur V., Nondestructive Characterization and Imaging of Wood, Series in Wood Science, Springer, Berlin, 2003, 354 p.

[4] Cano-Capri J., Burkart L.F., Distribution of gelatinous fibers as related to lean in southern red oak (Quercus falcata Michx.), Wood Sci. 7 (1974) 135-136.

[5] Casperson G., Probleme morphologischer Untersuchungen an Pappalholz, Faserforsch. Textiltech. 19 (1968) 345-350.

[6] Chantre G., Le bois de tension dans le genre Populus: effet clonal à un stade juvénile; conséquences d'une sélection précoce sur quelques paramètres technologiques, in: Thibaut B. (Ed.), Ve Séminaire Architecture, Structure, Mécanique de l'Arbre, LMGC, Université de Montpellier II, p. 187, 1993.

[7] Clair B., Thibaut B., Shrinkage of the gelatinous layer of poplar and beech tension wood, IAWA J. 22 (2001) 121-131.

[8] Clarke H., The distribution, structure, and properties of tension wood in beech (Fagus sylvatica L.), J. For. XI (1937) 85-93.

[9] Constant T., Mothe F., Badia M., Saint-Andre L., How to relate the standing tree shape to internal wood characteristics: proposal of an experimental method applied to poplar trees, Ann. For. Sci. 60 (2003) 371-378.

[10] Dadswell H.E., Wardrop A.B., What is reaction wood? Aus. For. 13 (1949) 22-33.

[11] Ferrand J.C., Étude des contraintes de croissance. Première partie: Méthode de mesure sur carottes de sondage, Ann. Sci. For. 39 (1982) 109-141.

[12] Fournier M., Chanson B., Thibaut B., Guitard D., Mesures des déformations résiduelles de croissance à la surface des arbres, en relation avec leur morphologie, Observations sur différentes espèces, Ann. For. Sci. 51 (1994) 249-266.

[13] Gonet B., Niektore wlasnosci technizne drewna napieciowego u buka, Dylwan 6 (1971) 25-35.

[14] Grzeskowiak V., Sassus F., Fournier M., Coloration macroscopique, retraits longitudinaux de maturation et de séchage du bois de tension du peuplier (Populus $\times$ euramericana cv. I214), Ann. Sci. For. 53 (1996) 1083-1097.

[15] Janin G., Ory J.M., Bucur V., Deshayes N., Luzet L., Remy P., Stosse L., Les fibres de bois de réaction. Partie I. Les fibres de bois de tension chez les feuillus. Ex.: Le hêtre, Rev. A.T.I.P. 44 (1990) 268-275.

[16] Jourez B., Technique de détection du bois de tension du peuplier sur échantillon massif, in: Thibaut B. (Ed.), Ve Séminaire Architecture, Structure, Mécanique de l'Arbre, LMGC, Université Montpellier II, p. $187,1993$.

[17] Jourez B., Le bois de tension 1. Définition et distribution dans l'arbre, Biotechnol. Agron. Soc. Environ. 1 (1997) 100-112.

[18] Jourez B., Riboux A., Leclercq A., Comparison of basic density and longitudinal shrinkage in tension wood and opposite wood in young stems of Populus euramericana cv. Ghoy when subjected to a gravitational stimulus, Can. J. For. Res. 31 (2001) 1676-1683.

[19] Kroll R.E., Ritter D.C., Gertjejansen R.O., Au K.C., Anatomical and physical properties of balsam poplar (Populus balsamifera L.) in Minnesota, Wood Fiber Sci. 24 (1992) 13-24.

[20] Leclercq A., La qualité du bois de quelques nouveaux cultivars belges de peuplier, Document interne, Station de Technologie Forestière de Gembloux, $1989,19 \mathrm{p}$.

[21] Lenz O., Le bois de quelques peupliers de culture en Suisse, Annales de l'Institut fédéral de recherches forestières (1954) 1-61.

[22] Marcok M., Kudela J., Cunderlik I., Identification of reaction beech wood by X-ray computed tomography, Holz Roh- Werkst. 54 (1996) 97-98

[23] Mariaux A., Vitalis-Brun A., Structure fine du bois de wapa en relation avec les contraintes de croissance, Bois For. Trop. 199 (1983) $43-56$.

[24] Norberg P.H., Meier H., Physical and chemical properties of the glatinous layer in tension fibres of aspen, Holzforshung 20 (1966) 174-178.

[25] Ohta S., Tension wood from the stems of Populus $\times$ canadensis aggr. with various degrees of leaning. I. Macroscopic identification and distribution of tension wood within stems, J. Japan Wood Res. Soc. 25 (1979) 610-614.

[26] Okuyama T., Yamamoto H., Iguchi M., Yoshida M., Generation process of growth stresses in cell walls II. Growth stresses in tension wood, Mokuzai Gakkaishi 36 (1990) 797-803.

[27] Panshin A.J., De Zeeuw C., Structure, identification, uses and properties of the commercial woods of the United States, in: Textbook of wood technology, McGraw-Hill, 1981, p. 16

[28] Polge H., Influence de l'élagage sur la duraminisation, la production de bois de tension et quelques autres propriétés du bois de peuplier I214, Ann. Sci. For. 42 (1985) 283-296.

[29] Ritter D.C., Kroll R.E., Gertjejansen R.O., Zones of gelatinous fibers in Populus balsamifera, Wood Fiber Sci. 25 (1993) 198-208.

[30] Sachsse H., Untersuchungen über den EunfluB der Ästung auf die Farbkern und Zugholzausbildung einiger Pappelsorten, Holz RohWerkst. 23 (1965) 425-434.

[31] Sacré E., Le bois de tension des peupliers, Bull. Inst. Agron. Stat. Rech. Gembloux XXVII (1959) 435-444.

[32] Sassus F., Fournier M., Thibaut B., Longitudinal growth strains and drying shrinkage in tension wood of poplars, IAWA Bull 16 (1995) $16-17$.

[33] Siebers A.M., The detection of tension wood with fluorescent dyes, Stain Technol. 35 (1960) 247-251.

[34] Von AufseB H., Mikroskopische Darstellung des Verholzungsgrades durch Färbemethoden, Holz Roh- Werkst. 31 (1973) 24-33.

[35] Washusen R., Ilic J., Waugh G., The relationship between longitudinal growth strain, tree form and tension wood at the stem periphery of ten-to eleven-year-old Eucalyptus globulus Labill, Holzforschung Holzverwertung 57 (2002) 308-316.

[36] Yoshida M., Okuda T., Okuyama T., Tension wood and growth stress induced by artificial inclination in Liriodendron tulipifera Linn. and Prunus spachiana Kitamura f. ascendens Kitamura, Ann. For. Sci. 57 (2000) 739-746. 